\title{
Quasi-Optimal Sizing of a Vehicle Fleet Considering Environmental Impact, Maintenance, and Eventual Containment Measures
}

\author{
Malek Ben Mechlia ${ }^{1, *}$, Jérémie Schutz ${ }^{1}$, Sofiene Dellagi ${ }^{1}$ and Anis Chelbi ${ }^{2}$ (I) \\ 1 LGIPM, Université de Lorraine, F-57000 Metz, France; jeremie.schutz@univ-lorraine.fr (J.S.); \\ sofiene.dellagi@univ-lorraine.fr (S.D.) \\ 2 RIFTSI Laboratory (LR20ES02), University of Tunis, ENSIT, Tunis 1008, Tunisia; anis.chelbi@planet.tn \\ * Correspondence: malek.ben-mechlia@univ-lorraine.fr
}

Citation: Mechlia, M.B.; Schutz, J.; Dellagi, S.; Chelbi, A. Quasi-Optimal Sizing of a Vehicle Fleet Considering Environmental Impact, Maintenance, and Eventual Containment Measures. Sustainability 2021, 13, 4384. https:// doi.org/10.3390/su13084384

Academic Editor: Mariano Gallo

Received: 7 March 2021

Accepted: 8 April 2021

Published: 14 April 2021

Publisher's Note: MDPI stays neutral with regard to jurisdictional claims in published maps and institutional affiliations.

Copyright: () 2021 by the authors. Licensee MDPI, Basel, Switzerland. This article is an open access article distributed under the terms and conditions of the Creative Commons Attribution (CC BY) license (https:// creativecommons.org/licenses/by/ $4.0 /)$.

\begin{abstract}
In this paper, $N$ types of vehicles having different environmental impacts and different failure rates are considered to perform a set of missions during a predefined period. The sizing problem of the fleet of vehicles is typically based on the literature for the environmental impact of each type of vehicle. This work intends to develop a model that allows considering not only the extent of recourse to non-polluting vehicles but also the preventive maintenance (PM) policy to be adopted for each of the $N$ types of vehicles. More specifically, the objective of this work consists in determining simultaneously the quasi-optimal number of vehicles of each type to be used, the duration of their use, and their average usage rate as well as the period according to which each type of vehicle should be submitted to preventive maintenance. A mathematical model is developed to express and optimize the expected total cost, which includes the costs related to acquisition, operating, maintenance, and environmental impact in addition to considering the resale value. Then, the situation of using the acquired vehicle fleet in a context of a health crisis with containment measures is considered. The latter make it impossible to perform preventive maintenance actions during the containment period. For such situations, given the accumulated degradation in absence of preventive maintenance, the cost model is modified to generate a new preventive maintenance plan to be applied for each vehicle after the containment exit. Numerical results related to fuel and electric vehicles of two brands (Renault and Nissan) are presented and discussed.
\end{abstract}

Keywords: road transportation; vehicle fleet; preventive maintenance; environmental impact; life cycle cost; sustainability; containment measures

\section{Introduction}

In order to consistently satisfy the expectations of their customers in terms of delivering the right quantities at the right time, companies are making great efforts related to logistics. Transportation is one of the most important logistics activities. It facilitates the creation of time and place utility in supply chains. Transportation service availability is critical to demand fulfilment. Keeping transportation costs reasonable contributes to competitiveness. As sustainability gains more and more attention, companies are looking for ways to optimize vehicles selection and utilization. Major focal points are the increased recourse to non-polluting vehicles, routing optimization, and preventive maintenance (PM) of vehicles. Research related to these issues has generally addressed them separately. Only a few authors considered two or the three of them simultaneously.

Rezg et al. 2014 [1] considered one type of vehicle required to complete a set of tours during a given period. The different circuits to realize are characterized by the time required to complete a tour as the types of roads, which have an impact on the degradation process of the vehicles. The authors developed a mathematical model in order to derive the optimal PM period for the vehicle. Three levels of operation have been considered in order to illustrate the road influence on the reliability and maintenance of the vehicle. 
Troudi et al. 2015 [2] sequentially established the optimal distance to be traveled as well as the optimal number of PM actions to be performed on the vehicle taking into account two significant factors: the type of road and the climatic conditions. They analytically modeled the influence of these two factors on the vehicle's failure rate.

Dhahri et al. 2015 [3] worked on a vehicle routing problem with time windows with PM. The authors developed a scheduling model for situations where a PM action is performed on the vehicles at a given time on their way between the starting point (depot) and the end point (the customer). They proposed a mathematical model and used a variable neighborhood search metaheuristic to find a new planning that minimizes the deviation from the original planning (without maintenance) in terms of total traveled distance and number of vehicles. In a similar context, Dhahri et al. 2016 [4] tackled the same problem with another mathematical formulation.

Ndhaief et al. 2017 [5] considered an urban distribution center (UDC) which must satisfy daily demand of its customers in a given urban area over a finite time span. A collaborative approach with a subcontractor is proposed to deal with the situations where the UDC cannot satisfy the total demand during a given period due to lack of capacity that can be caused by vehicles repair or PM. The choice of the subcontractor depends on capacity, distance, and environmental impact. The authors developed a mathematical model and a sequential solving procedure in order to determine the most economic products distribution plan and PM schedule for the vehicles. Penalties in case of late deliveries are also considered in the model.

Rashidnejad et al. 2018 [6] proposed a bi-objective mixed integer non-linear programming model for PM scheduling of geographically distributed assets taking into account the vehicle routing problem. The model aims at simultaneously minimizing the total cost (failure, maintenance, and travel costs) and maximizing the assets availability. The non-dominated sorting genetic algorithm II (NSGA-II) has been used to solve the problem. The model and the solving procedure have been applied to a case of a third party company in charge of the maintenance of the ATMs of an Iranian bank in Tehran city (210 ATMS spread over an area of approximately $1600 \mathrm{~km}^{2}$ ).

Jbili et al. 2018 [7] proposed an integrated strategy of vehicle routing and maintenance considering situations of transcontinental transportation where heavy vehicles travel over long distances between cities in a difficult environment favoring a non-negligible probability of failure of critical components. They concurrently determine the optimal delivery sequence and the optimal sequence of PM actions (i.e., the customers' cities at which PM should be performed) which minimize the expected total cost rate when considering penalties on late arrival and transportation and maintenance costs. A genetic algorithm is proposed to solve instances of the problem involving an important number of customers to be delivered.

Vujanović et al. 2018 [8] developed a methodology for integrated vehicle fleet maintenance management with the aim of increasing the vehicles efficiency (in terms of fuel consumption) while improving maintenance management. Their approach is based on multicriteria assessment and improvement of the fleet maintenance management system. Three sets of criteria were proposed related to transport process, maintenance process, and roadworthiness.

As sustainability is becoming an inevitable issue in the business world, many efforts are being made by companies to reduce the environmental impact of their logistics, particularly in transportation. The gaseous emissions generated by different vehicles include carbon dioxide $\left(\mathrm{CO}_{2}\right)$ and nitrogen oxides $\left(\mathrm{NO}_{\mathrm{X}}\right)$.

Wang et al. 2019 [9] addressed the carbon emissions in port areas. They were interested in the relationship between the service performed during unloading/loading the vessel and the carbon emissions. They considered that carbon emissions come mainly from the land area of the port (the dock cranes and yard trucks) and the water area (the vessel). The authors developed two objective functions to be minimized: the total carbon emission and the average waiting time in port for each vessel. 
Sawik et al. 2017 [10] deals with multicriteria optimization of fleet size. The adopted criteria are related to the environmental impact such as fuel use, carbon emissions, and noise production. The considered vehicles generate different amounts of carbon emissions and noise. Mixed integer programming models are established and solved using AMPL programming language and CPLEX based on data from a Spanish food distribution company. The results show some balance between truck types, fleet size utilization of fuel, carbon, and noise emissions.

One of the options adopted more and more frequently by companies to reduce the hurtful effects on the environment caused by their transportation vehicles consists in the use of hybrid and/or electric ones.

Donateo et al. 2014 [11] worked on the estimation of the environmental impact of an electric city car during six months of testing in an Italian city. They presented a methodology based on three steps: the first one is the measurement of the electric consumption on board of the vehicle on a total of 42 tests that differ according to the type of route, traffic conditions, and use of auxiliaries (lights, heating, air conditioning, rear window heating). The second step is the definition of the electricity generation mix of each recharging events. This information was obtained thanks to the ability of the recharging station to measure and store usage data. Finally, the third step is the evaluation of the emission levels, (i.e., mass of pollutants associated to the production of $1 \mathrm{kWh}$ of electricity) in different days and time slots according to the corresponding load levels. The obtained results were compared with the limits set by the European legislation on conventional cars. They clearly showed a strong advantage of using electric vehicles instead of conventional ones in urban traffic conditions.

Rios-Torres et al. 2019 [12] worked on fuel consumption for three different driving styles (normal, calm, and nervous) for electric and hybrid vehicles. This work aimed to estimate the fuel consumption of the mentioned vehicles using customized driving cycles extracted from real data. They obtained vehicle drive cycles from a large-scale US survey that contains actual GPS-based driving records. These driving cycles were assigned to one of three categories and then used with a driver-vehicle simulation that captures driver decisions (vehicle speed during a trip), vehicle dynamics, and powertrain to estimate vehicle fuel consumption. The results show that the driving style has a direct impact on fuel consumption. Indeed, fuel consumption of conventional vehicles can be reduced by $13 \%$ during calm urban driving but increase by almost $34 \%$ during nervous highway driving compared to standard driving cycles.

In the same context, different outcomes have been found by Prud'homme and Koning 2012 [13]. They developed a model to estimate the specific costs related to an electric car, relative to a similar fuel car, for the consumer and for society. The following parameters were considered. For electric cars: purchase cost, electrical efficiency, battery cost, price of electricity, and the $\mathrm{CO}_{2}$ content of electricity. For fuel cars: purchase cost, fuel efficiency, fuel prices, local pollution costs, and $\mathrm{CO}_{2}$ emissions. The adopted methodology is a comparative study between the two types of cars from three different perspectives: consumer costs, socioeconomic costs, and $\mathrm{CO}_{2}$ emissions, based on a car providing about the same level of service during the same period of time. The obtained results showed that the fuel vehicle outperforms the pure electric car. Indeed, the authors found that over the lifetime of a vehicle, it will cost around 12,000 euros more for the consumer, and 15,000 euros more for society. This is partly due to the important average $\mathrm{CO}_{2}$ content of electricity in Europe.

For more insights, readers may also consult the recent survey about the green vehicle routing problem (G-VRP) provided by Macrina et al. 2020 [14].

Table 1 below summarizes most of the abovementioned contributions in the literature indicating, for each work, the subject(s) it tackles in relation to the subject of this paper. 
Table 1. Summary of related contributions.

\begin{tabular}{|c|c|c|c|c|}
\hline Authors & Fleet Sizing & $\begin{array}{l}\text { Vehicles } \\
\text { Typology }\end{array}$ & PM Strategy & $\begin{array}{c}\text { Vehicle } \\
\text { Routing Problem }\end{array}$ \\
\hline $\begin{array}{l}\text { Prud'homme and Koning } \\
\qquad 2012 \text { [13] }\end{array}$ & - & $\checkmark$ & - & - \\
\hline Donateo et al. 2014 [11] & - & $\checkmark$ & - & - \\
\hline Rezg et al. 2014 [1] & - & - & $\checkmark$ & $\checkmark$ \\
\hline Troudi et al. 2015 [2] & - & - & $\checkmark$ & $\checkmark$ \\
\hline Dhahri et al. 2015 [3] & - & - & $\checkmark$ & $\checkmark$ \\
\hline Dhahri et al. 2016 [4] & - & - & $\checkmark$ & $\checkmark$ \\
\hline Ndhaief et al. 2017 [5] & - & - & $\checkmark$ & - \\
\hline Sawik et al. 2017 [10] & $\checkmark$ & $\checkmark$ & - & $\checkmark$ \\
\hline Rashidnejad et al. 2018 [6] & - & - & $\checkmark$ & $\checkmark$ \\
\hline Jbili et al. 2018 [7] & - & - & $\checkmark$ & $\checkmark$ \\
\hline Vujanović et al. 2018 [8] & - & - & $\checkmark$ & - \\
\hline Rios-Torres et al. 2019 [12] & - & $\checkmark$ & - & - \\
\hline This paper & $\checkmark$ & $\checkmark$ & $\checkmark$ & - \\
\hline
\end{tabular}

\section{Problem Description and Targeted Contribution}

In this framework of sustainability in transportation, the objective of this work is to develop an integrated model which allows quasi-optimal sizing of a vehicle fleet made of $N$ types of vehicles (electric, fuel, hybrid, etc.) having different environmental impacts and different reliabilities. These vehicles are to be acquired to perform a set of missions during a predefined period of some years. In the literature, the sizing problem of the fleet of vehicles is typically based on the environmental impact of each type of vehicles. The targeted contribution through the developed model is to consider not only the environmental impact of the vehicles, but also their reliability and maintenance. Hence, the objective is to capture simultaneously two major issues, which are the extent of recourse to nonpolluting vehicles, and the PM policy to be adopted for each of the $N$ types of vehicles. More specifically, the aim is to simultaneously determine the optimal number of vehicles of each type to be acquired, the duration of their use, and the associated average usage rate before they are resold as well as the PM period for each type of vehicle, such as the total expected cost is minimized. To the best of knowledge of the authors, such an approach of simultaneous determination of the fleet size and typology, the PM strategy, and the possession duration before resale does not exist in the literature (see Table 1 above).

Moreover, as the widely spread COVID-19 pandemic that affected nearly most of the world population is still causing a lot of uncertainty, yielding containment measures that can be taken at any time by governments, an eventual containment can be imposed during the period of use of the acquired vehicle fleet, making it impossible to perform PM actions during the containment (only repairs are allowed to avoid stopping the missions of the vehicles; repairs are part of the vital logistics activities that must be maintained during the containment). For such a context, the cost model is modified to adjust the PM plan to be followed for each vehicle after the containment exit.

The remainder of this paper is organized as follows. Section 2 focuses on the description of the problem and the targeted contribution. Section 3 describes the mathematical model with the working assumptions and used notation. In Section 4, a numerical example and a sensitivity study are proposed to illustrate the use of the analytical model. Section 5 will be dedicated to the determination of a new PM plan to be adopted for each vehicle in situations of a health crisis imposing containment measures forcing the interruption of PM during the containment. Finally, concluding remarks and potential extensions of this work are presented in the last section.

\section{The Mathematical Model}

\subsection{Used Notation}

The decision variables are defined as follows: 
- $X_{i}$ : Number of vehicles of type $i, i \in\{1, \ldots, N\}$, with $X_{i} \in \mathbb{N}$

- $Y_{i}$ : Number of months of use of each vehicle of type $i, i \in\{1, \ldots, N\}$, with, $Y_{i} \in \mathbb{N}$

- $\quad m_{i}$ : The PM period to be adopted for a vehicle of type $i$ (months) with $m_{i} \in \mathbb{N}^{*}$

- $v_{i}$ : The average usage rate $(\mathrm{km} / \mathrm{month})$ associated with a vehicle of type $i, i \in\{1, \ldots, N\}$ The following notation is used in the mathematical model:

- $T_{M a x}$ : Period during which the mission has to be performed (months)

- $\quad N$ : Number of vehicle types, with $i$ is considered the type of vehicle $i \in\{1, \ldots, N\}$

- $K$ : The minimum total number of kilometers to be traveled by all types of vehicles $(\mathrm{km})$

- $\quad E^{-} C_{N}$ : Expected total cost (monetary units 'm.u')

- $\quad C_{A i}$ : Acquisition cost of a vehicle of type $i$ (m.u)

- $\quad C_{O i}$ : Operating cost of a vehicle of type $i$ (m.u)

- $\quad C_{M i}$ : Expected total maintenance cost for a vehicle of type $i(\mathrm{~m} . \mathrm{u})$

- $\quad C_{M C i}$ : Expected cost of corrective maintenance for a vehicle of type $i(\mathrm{~m} . \mathrm{u})$

- $\quad C_{M P i}$ : Expected cost of PM for a vehicle of type $i$ (m.u)

- $C_{E i}$ : Expected cost of environmental impact for a vehicle of type $i(\mathrm{~m} . \mathrm{u})$

- $\quad V_{R i}$ : Resale value of a vehicle of type $i$ (m.u)

- $\mu_{c i}$ : The average duration of a corrective maintenance action for a vehicle of type $i$ (months)

- $\quad \mu_{p i}$ : The average duration of a PM for a vehicle of type $i$ (months)

- $\lambda_{i}$ : The failure rate function of a vehicle of type $i$

- $v_{\text {imin }}$ : The minimum average usage rate associated with a vehicle of type $i(\mathrm{~km} / \mathrm{month})$

- $v_{\text {imax }}$ : The maximum average usage rate associated with a vehicle of type $i(\mathrm{~km} / \mathrm{month})$

- $T_{i}$ : The possession duration of each vehicle of type $i$ (months)

- $\varnothing\left(Y_{i}, m_{i}\right)$ : The average number of breakdowns (minimal repairs) over a period of use of a vehicle of type $i$ for a given PM period $m_{i}$

- $1_{X}$ : Indicator function equal to $\left\{\begin{array}{l}1 \text { if } X_{i} \geq 1 \\ 0 \text { if } X_{i}=0\end{array}\right.$

- $1_{\gamma}$ : Indicator function equal to $\left\{\begin{array}{l}1 \text { if } Y_{i} \geq 1 \\ 0 \text { if } Y_{i}=0\end{array}\right.$

- $\quad\lfloor$.$\rfloor : rounds to the nearest inferior integer$

- $\quad\lceil$.$\rceil : rounds to the nearest superior integer$

\subsection{Working Assumptions}

The following assumptions are considered:

- All the vehicles of each type will travel a different number of kilometers $\left(X_{i} \cdot Y_{i} \cdot v_{i}\right)$, $i \in\{1, \ldots, N\}$. This number of kilometers will be equally distributed over the $X_{i}$ vehicles of the same type $i$. This will allow a homogeneous workload for each type of vehicles and may facilitate the resale.

- PM is imperfect. PM actions consist in the renewal of certain components of the vehicle.

- After each minimal repair, the vehicle is back to operation with the same failure rate it had before failure.

- While keeping generality considering any $N$ types of vehicles in the mathematical formulation of the expected total cost, only two types of vehicles (fuel and electric) are considered in the development of the cost models related to the operation and the environmental impact of the vehicles.

\subsection{The Cost Model}

As a reminder, the objective consists in minimizing the expected total cost including acquisition, maintenance, operating, and environmental impact costs in addition to considering the resale value. This has to be done according to the decision variables, which are the number of vehicles of type $i\left(X_{i}\right)$, the number of months of use of a vehicle of type $i$ $\left(Y_{i}\right)$, the PM period to be adopted for a vehicle of type $i\left(m_{i}\right)$, and the average usage rate 
of vehicles of type $i\left(v_{i}\right)$. The solution to be derived must satisfy the fact that at least (K) kilometers must be traveled during a specified period $\left(T_{\max }\right)$ with a usage rate $\left(v_{i}\right)$.

Hence, the mathematical formulation of the problem is as follows:

$$
\min \operatorname{ETC}_{N}=\sum_{i=1}^{N} X_{i} \cdot\left[C_{A i}+C_{M i}+C_{O i}+C_{E i}-V_{R i}\right]
$$

subject to

$$
\begin{gathered}
\sum_{i=1}^{N} X_{i} \cdot Y_{i} \cdot v_{i} \geq K \\
T_{i} \leq T_{\max } \forall i=1, \ldots, N \\
v_{\text {imin }} \leq v_{i} \leq v_{\text {imax }} \forall i=1, \ldots, N \\
Y_{i} \leq 1_{X} \cdot \min \left(T_{\max }, \frac{K}{v_{i}}\right) \forall i=1, \ldots, N
\end{gathered}
$$

The objective function (1) is the sum of acquisition, maintenance, operation, and environmental impact costs minus the resale value for all vehicles.

Constraint (2) ensures that the number of kilometers traveled by all vehicles is at least equal to the total number of kilometers to be traveled $(K)$.

Constraint (3) is a set of $N$ constraints that state that that the possession duration of vehicles of each type $i$ is shorter than or equal to the period within which the missions must be performed $\left(T_{\max }\right)$. In other words, the missions may be completed, and the vehicles sold before $T_{\max }$.

Constraint (4) is a set of $N$ constraints which ensure that the average usage rate is bounded between a minimum usage rate and a maximum usage rate.

Constraint (5) is also a set of $N$ constraints stating that the number $\left(Y_{i}\right)$ of months of use of a vehicle of type $i$ will be 0 , if no vehicle of this type is acquired.

In the following subsections, the expressions of each term of the model above are developed.

\subsubsection{The Expected Total Maintenance Cost Per Vehicle}

The proposed maintenance strategy consists in performing imperfect PM actions on the vehicle every $m_{i}$ months. These preventive actions consist in replacing certain components of the vehicle by identical new ones, which yields to what is called a partial renewal. The latter decreases the failure rate of the vehicle to a certain extent. In the case of breakdowns between consecutive PM actions, minimal repairs are performed restoring the vehicle to a working state while keeping its failure rate at the same level as before the breakdown.

The expected total maintenance cost per vehicle is given by

$$
C_{M i}=C_{M C i} \cdot \varnothing\left(Y_{i}, m_{i}\right)+C_{M P i} \cdot\left\lfloor\frac{Y_{i}}{m_{i}}\right\rfloor .
$$

Using the partial renewal PM model developed by Gertsbakh 2013 [15], the average number of minimal repairs, $\varnothing\left(Y_{i}, m_{i}\right)$, over a period of use of a vehicle of type $i$ for a given PM period $m_{i}$ (see Figure 1), can be expressed as

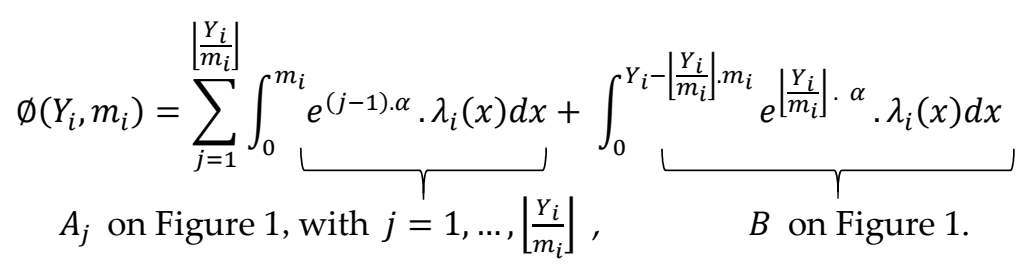

where $e^{\alpha}$ is considered as a "degradation" factor which is $>0$. Gertsbakh 2013 [15] shows how $\alpha$ can be empirically found using the linear regression technique. 
Equation (7) above models the fact that, on one hand, the partial renewal induces a reduction in the failure rate of the vehicle and on the other hand, the average number of breakdowns (minimal repairs) is incremented as one moves from one PM period to the next one (see Figure 1 below).

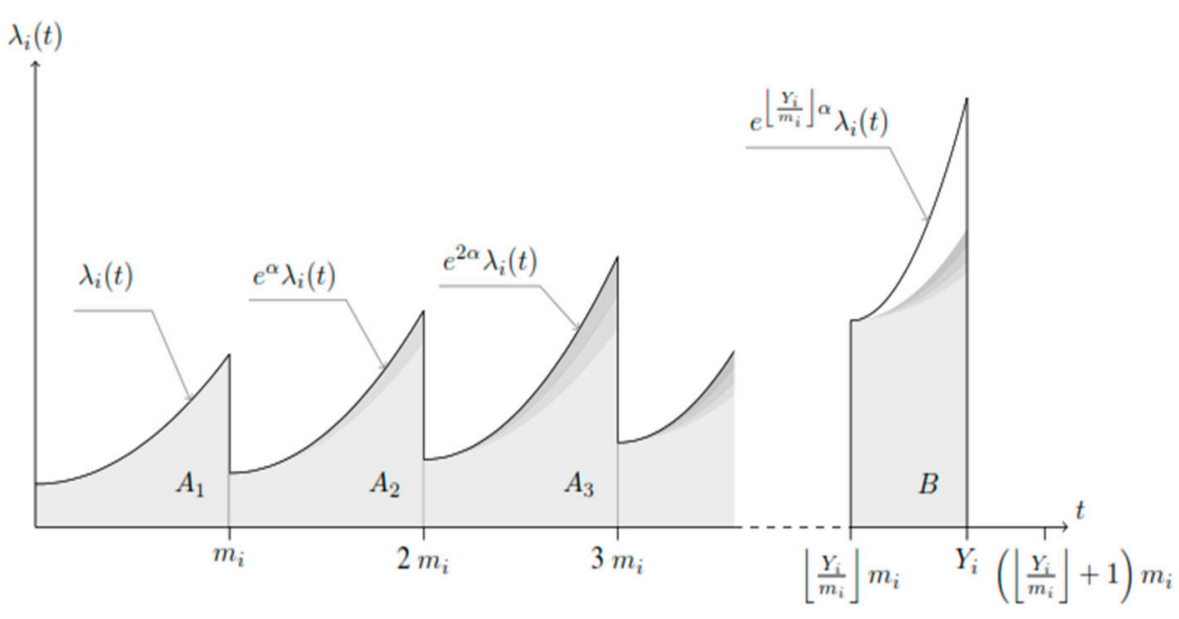

Figure 1. Evolution of the vehicle failure rate with partial renewals every preventive maintenance (PM) period $m_{i}$

\subsubsection{The Expected Operating Cost}

The operating costs depend on several parameters which differ according to the type of vehicle. Without loss of generality regarding the cost model Equations (1)-(5), which considers $N$ types of vehicles, this study will be limited to two types of vehicles ( $i=1 \mathrm{for}$ the fuel vehicle and $i=2$ for the electric vehicle).

Based on the existing literature, the expression of the operating costs for each of these two types of vehicles in the context of the present work can be formulated as follows:

- Fuel type: The fuel vehicle is characterized by its fuel efficiency, which is expressed by the number of kilometers driven per unit of fuel consumed ( $\mathrm{km} / \mathrm{liter}$ ) according to the American standard, or in (liters $/ 100 \mathrm{~km}$ ) which is commonly used in Europe. Based on the formulation developed by (Prud'homme and Koning 2012) [13], the following equation presents the operating cost for a fuel vehicle $(i=1)$ :

$$
C_{O 1}=\left(\frac{Y_{1} \cdot v_{1}}{e f f_{1}}\right) \cdot C_{U F}
$$

where

- $\quad$ ef $f_{1}$ : Fuel efficiency $(\mathrm{km} / \mathrm{liter})$

- $C_{U F}$ : Unit cost of fuel (m.u/liter)

We recall that

- $Y_{1}$ : Number of months of use of a fuel type vehicle

- $v_{1}$ : The average usage rate associated with the fuel type vehicle $(\mathrm{km} / \mathrm{month})$

- Electric type: The operation of an electric vehicle is characterized by the electric consumption and the specificity of the used technology (the battery autonomy, the recharge cycles, etc.).

The expected operating cost of electric vehicles can be expressed as the sum of the average cost of the batteries to be used and the average recharging cost over the usage period.

$$
C_{\mathrm{O} 2}=C_{\text {unit }} \cdot\left\lfloor\frac{N b_{\text {AverCh }}}{N b_{\text {Max Ch }}}\right\rfloor+C_{c h} \cdot N b_{\text {AverCh }}
$$

where 
- $\quad C_{c h}$ : Fuel efficiency $(\mathrm{km} /$ liter)

- $\mathrm{Nb}_{\text {AverCH}}$ : The average number of recharging over the usage period

- $C_{\text {unit: }}$ : The cost of the battery (m.u)

- $\quad N b_{M a x C h}$ : The maximum allowable number of recharging

Where:

$$
N b_{\text {AverCh }}=\left\lfloor\frac{Y_{2} \cdot v_{2}}{\theta}\right\rfloor
$$

where

- $\theta$ : The average battery autonomy $(\mathrm{km})$

We recall that:

- $\quad Y_{2}$ : Number of months of use of one electric type vehicle

- $v_{2}$ : The average usage rate associated with an electric type vehicle $(\mathrm{km} / \mathrm{month})$

\subsubsection{The Environmental Impact Cost}

The major environmental impact that is considered in this work is $\mathrm{CO}_{2}$ emissions.

Referring to the work of (Prud'homme and Koning 2012) [13], the corresponding cost is expressed as follows:

$$
C_{E i}=C U_{\mathrm{CO} 2} \cdot Y_{i} \cdot v_{i} \cdot g_{i} \cdot\left(\frac{1}{e f f_{i}}\right)
$$

where

- $\quad \mathrm{CU}_{\mathrm{CO} 2}$ : The cost of the nuisance caused by $1 \mathrm{~kg}$ of $\mathrm{CO}_{2}$ emitted into the air $(\mathrm{m} . \mathrm{u} / \mathrm{kg})$

- $\quad g_{i}: \mathrm{CO}_{2}$ emission in $\left(\mathrm{kg} /\right.$ liter) for fuel vehicles $(i=1)$ and $\mathrm{CO}_{2}$ content of electricity in $(\mathrm{kg} / \mathrm{kWh})$ for electric vehicles $(i=2)$

- $\quad$ ef $f_{i}$ : The energetic efficiency (number of kilometers traveled per liter for fuel type $(\mathrm{km} /$ liter) or per kilowatt-hour for electric type $(\mathrm{km} / \mathrm{kWh})$ depending on the type of vehicle)

\subsubsection{The Resale Value}

We express the resale value of a vehicle as follows:

$$
V_{R i}=C_{A i} \cdot \sum_{k}\left(a_{i k} \cdot T_{i}+b_{i k}\right) \cdot 1_{\left[12 .(k-1) \leq T_{i} \leq 12 . k\right]}
$$

where

- $\quad V_{R i}$ : The resale value of a vehicle of type $i$ (m.u)

- $\quad C_{A i}$ : Acquisition cost of a vehicle of type $i$ (m.u)

- $K$ : The indicator of year of the resale of a vehicle of type $i$ (years)

- $T_{i}$ : The possession duration of a vehicle of type $i$ (months)

- $\quad\left(a_{i k}\right)$ and $\left(b_{i k}\right)$ : The depreciation parameters of vehicles of types $i$ according to time. Theses parameters are estimated as the average discounts presented in Table 1 (referring to $[16,17])$.

- $1_{\left[12 .(k-1) \leq T_{i} \leq 12 . k\right]}$ : Indicator function equal to $\left\{\begin{array}{c}1 \text { if } T_{i} \in[12 .(k-1), 12 . k] \\ 0 \text { otherwise }\end{array}\right.$

Table 2 indicates the average discount of fuel and electric vehicles. One can notice that a new fuel vehicle loses up to $25 \%$ of its value during the first year. On the other hand, compared with a new electric vehicle, a fuel vehicle depreciates at a slower pace. 
Table 2. The average discount of new vehicles per year $([16,17])$.

\begin{tabular}{cccc}
\hline \multicolumn{2}{c}{ Fuel Vehicle } & \multicolumn{2}{c}{ Electric Vehicle } \\
\hline Years & Discount \% & Years & Discount \% \\
\hline 1 & $-25 \%$ & 1 & $-25 \%$ \\
2 & $-15 \%$ & 2 & $-17 \%$ \\
3 & $-10 \%$ & 3 & $-20 \%$ \\
4 & $-10 \%$ & 4 and + & $-33 \%$ \\
5 & $-7 \%$ & & \\
6 and + & $-7 \%$ & & \\
\hline
\end{tabular}

$T_{i}$, the possession duration of a vehicle of type $i$ includes the number of months of use of the vehicles of type $i\left(Y_{i}\right)$ and the duration of all preventive and corrective maintenance actions performed on the vehicles. It is expressed as follows:

$$
T_{i}=\left\lceil Y_{i}+\varnothing\left(Y_{i}, m_{i}\right) \cdot \mu c_{i}+\left\lfloor\frac{Y_{i}}{m_{i}}\right\rfloor \cdot \mu p_{i}\right\rceil
$$

where $\varnothing\left(Y_{i}, m_{i}\right)$, previously expressed by Equation (7), represents the average number of breakdowns (minimal repairs) over the usage period of a vehicle of type $i$ for a given PM period $m_{i}$.

Hence, using Equations (6)-(13), and considering $N=2$ types of vehicles (fuel and electric types), the analytical expression of the expected total cost Equation (1) is given below as a function of the decision variables $X_{i}, Y_{i}, m_{i}$ and $v_{i}(i=1,2)$ :

$$
\operatorname{ETC}_{(N=2)}=\left[\begin{array}{c}
\sum_{i=1}^{2} X_{i} \cdot C_{A i} \\
+\sum_{i=1}^{2} X_{i} \cdot\left(C_{M C i} \cdot \varnothing\left(Y_{i}, m_{i}\right)+C_{M P i} \cdot\left\lfloor\frac{Y_{i}}{m_{i}}\right\rfloor\right) \\
+X_{1} \cdot\left(\frac{Y_{1} \cdot v_{1}}{e f f_{1}}\right) \cdot C_{U F}+X_{2} \cdot\left(C_{u n i t} \cdot\left|\frac{N b_{A v e r C h}}{N b_{M a x C h}}\right|+C_{c h} \cdot N b_{A v e r C h}\right) \\
+\sum_{i=1}^{2} X_{i} \cdot C U_{\mathrm{CO}_{2}} \cdot Y_{i} \cdot v_{i} \cdot g_{i} \cdot\left(\frac{1}{e f f_{i}}\right) \\
-\sum_{i=1}^{2} X_{i} \cdot C_{A i} \cdot \sum_{k}\left(a_{i k} \cdot T_{i}+b_{i k}\right) \cdot 1_{\left[12 \cdot(k-1) \leq T_{i} \leq 12 \cdot k\right]}
\end{array}\right]
$$

\section{Numerical Example}

As presented in the previous section, the mathematical model involves $(4 \times N)$ decision variables $\left(X_{i}, Y_{i}, m_{i}\right.$, and $\left.v_{i}, i \in\{1, \ldots, N\}\right)$, which generate a huge number of combinations, making it very hard, if not impossible, to obtain the optimal solution in a reasonable amount of time. The mathematical model developed in this paper is known as part of non-convex mixed integer non-linear programming (MINLP) problems. They are considered as NP-Hard.

Several metaheuristics exist to solve these problems such as cuckoo search, grey wolf optimizer, and many more. The chosen method is the genetic algorithm (GA) that has been widely used in the literature to deal with MINLP problems and which is well described by Ponsich et al. 2007 [18]. The GA is based on the principle of Darwinian evolution. From a set of randomly generated initial solutions, genetic operations (crossovers and mutations) are performed to generate child solutions that are potentially better. The solution evaluation is based on a fitness function Equation (1). To ensure a suitable solution, it is usual to retain the best solutions (elites) throughout the generations.

To solve this MINLP problem, the ga function (http:/ /www.mathworks.com/help/ gads / genetic-algorithm.html (accessed on 6 March 2021)), proposed by the global optimization toolbox of MATLAB software (R2019a) proven to be suitable after having extensively tested it. Regarding the ga function, the integer programming requires specific adjustments for population creation and genetic operations, based on the work of Deep et al. 2009 [19]. 
An important change is also applied for the evaluation of solutions. The fitness function is replaced by a penalty function to be minimized (Deb 2000) [20]. These modifications are automatically controlled by MATLAB.

An illustrative numerical example and the obtained results are presented below.

\subsection{Input Data}

The following numerical example is based on a set of input data based on realistic settings. The links to the websites from which the values of most of the parameters are derived are given in the Appendix A (Table A1). The input data are presented in Tables 3 and 4. Two types of vehicles (fuel and electric) are considered $(N=2)$ and missions to be performed over a period $T_{\text {Max }}$ of 5 years (60 months). Note that the parameters related to energetic efficiency and $\mathrm{CO}_{2}$ emissions or content depending on the type of vehicle are the same parameters used by Prud'homme and Koning 2012 [13].

Table 3. Input data of the numerical examples.

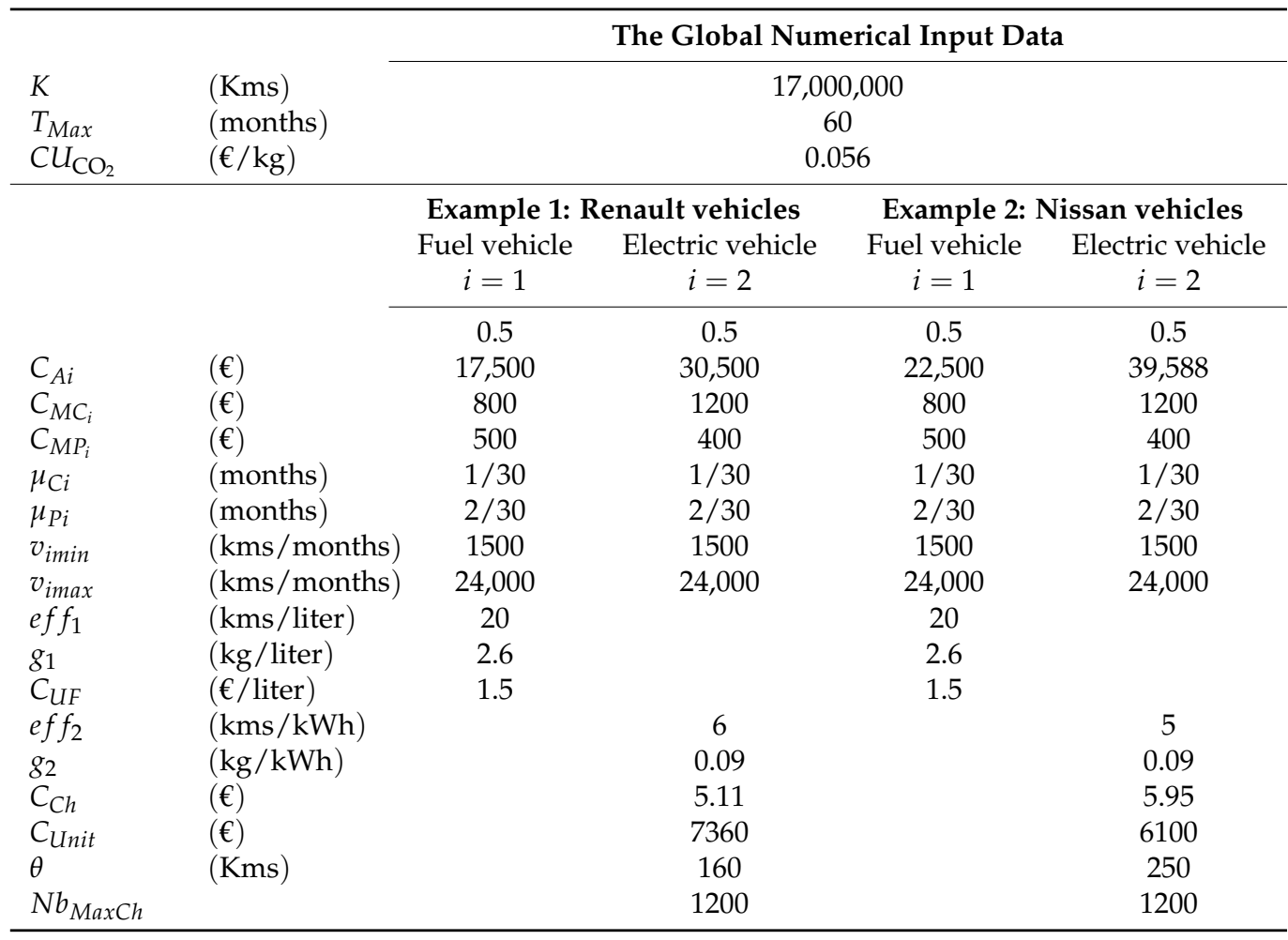

Table 4. Parameters of the Weibull time to failure distribution of the vehicles.

\begin{tabular}{cccc}
\hline & Scale Parameter & Shape Parameter & Mean Time to Failure (Months) \\
\hline Fuel vehicle & 9 & 2 & 7.98 \\
Electric vehicle & 13 & 2 & 11.52 \\
\hline
\end{tabular}

Note that the vehicles time to failure probability distribution is a Weibull distribution with an increasing failure rate with the following parameters for each type of vehicle:

\subsection{The Obtained Results}

Based on the ga function with these particular options chosen (MaxGenerations = 100,000) and MaxStallGenerations = Inf), a quasi-optimal solution (Figure 2 and Table 5) is obtained, in a reasonable amount of time (based on a computer equipped with a dual-core $2.9 \mathrm{GHz}$ Intel Core i5 processor with $16 \mathrm{~GB} 2133 \mathrm{MHz}$ of memory) of about 15 min after the 63,458 th and the 58,964th generations for examples 1 and 2, respectively. After numerous 
tests, it was not necessary to increase the number of generations in relation to the obtained solutions and the elapsed time.

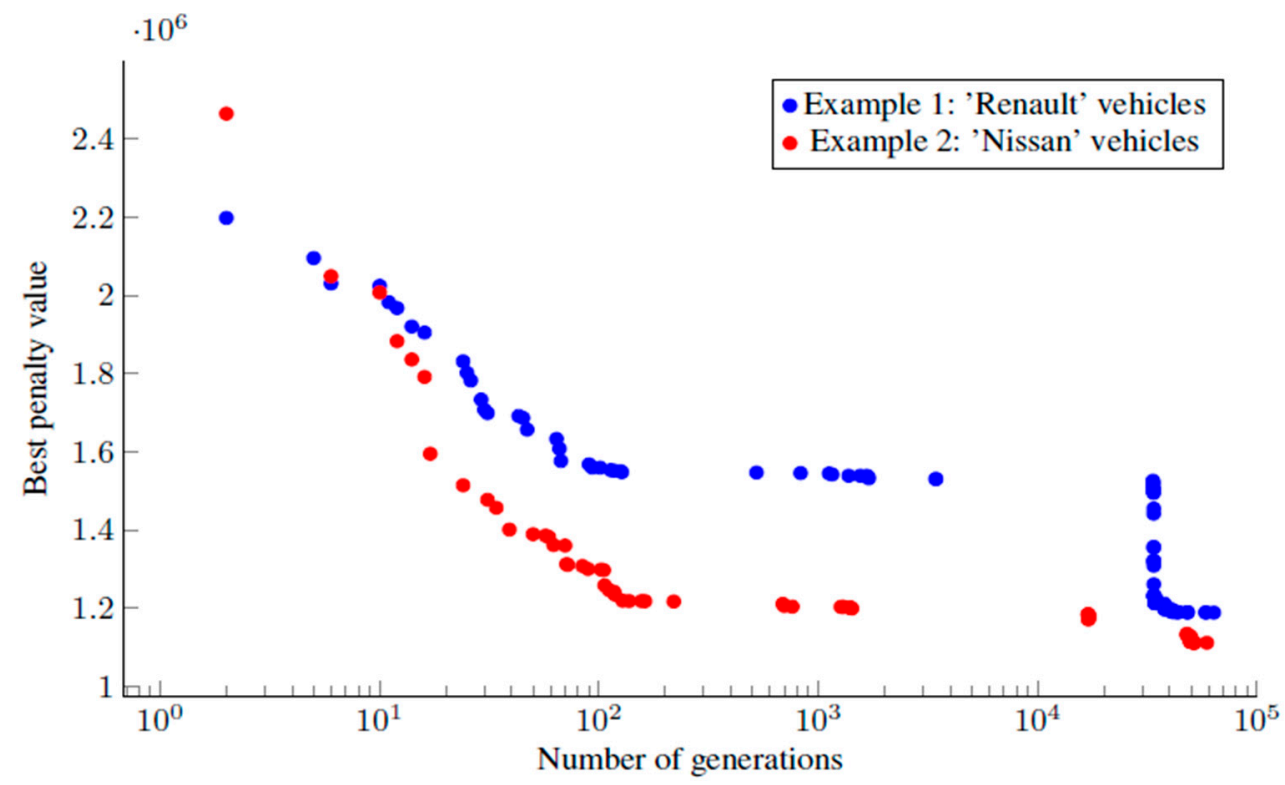

Figure 2. Results obtained with the used metaheuristic.

Table 5. The obtained results.

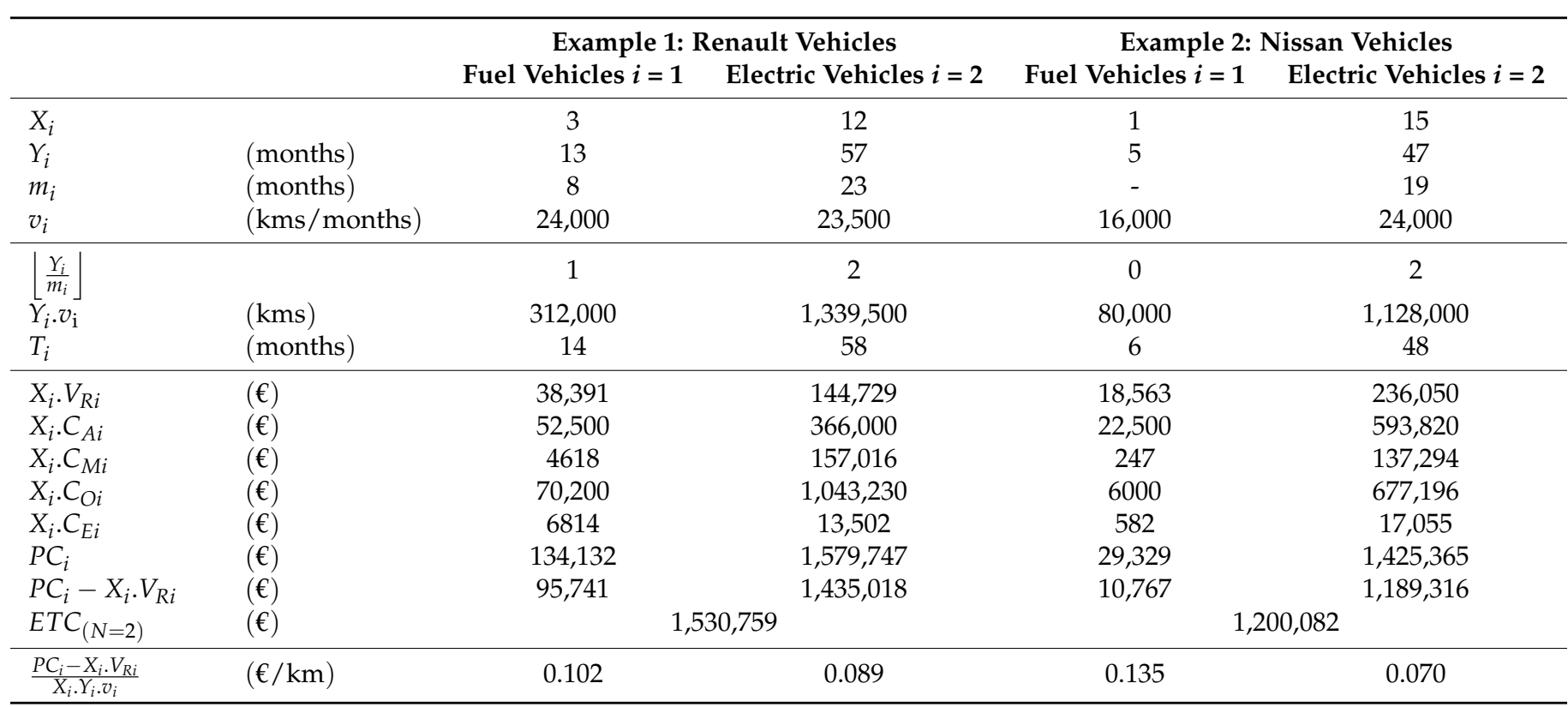

As a reminder, the decision variables $\left(X_{i}\right),\left(Y_{i}\right),\left(m_{i}\right)$, and $\left(v_{i}\right)$ represent, for each vehicle of type $i$, the total number of vehicles, the number of months of use of the vehicles, the PM period to be adopted for each vehicle, and the average usage rate assigned to each vehicle, respectively. The obtained quasi-optimal values of these decision variables are presented in Table 5.

The same table presents, for each type of vehicle, the number of PM actions $\left\lfloor\frac{Y_{i}}{m_{i}}\right\rfloor$ to be performed on each vehicle, the number of kilometers to be traveled by each vehicle $\left(Y_{i} . v_{i}\right)$, and the possession duration $T_{i}$.

Finally, the table provides the resale value, $X_{i} . V_{R i}$, and the expected partial costs for all the vehicles of each type (acquisition, $X_{i} \cdot C_{A i}$, maintenance, $X_{i} \cdot C_{M i}$, operation, $X_{i}$. $C_{O i}$, 
and environmental impact, $\left.X_{i} \cdot C_{E i}\right)$, the total of these expected partial costs, $P C_{i}$, as well as the expected total cost $\left(E T C_{(N=2)}\right)$.

Regarding the Renault vehicles, the obtained results show that the quasi-optimal strategy is to acquire 3 fuel vehicles and 12 electric ones. The fuel vehicles will be used for 13 months, each one of them is expected to travel a total distance of $312,000 \mathrm{~km}$ at an average usage rate of $24,000 \mathrm{~km} / \mathrm{month}(800 \mathrm{~km} /$ day), with a partial renewal action at the 8 th month. The electric vehicles will be used 57 months, each one of them is expected to travel a total distance of $1,339,500 \mathrm{~km}$ at an average usage rate of $23,500 \mathrm{~km} / \mathrm{month}(783 \mathrm{~km} /$ day), and undergo a partial renewal every 23 months. By doing so, the expected total costs per type of vehicle will be respectively $95,741 €$ for the fuel vehicles (i.e., $0.102 € / \mathrm{km}$ ) and $1,435,018 €$ for the electric vehicles (i.e., $0.089 € / \mathrm{km}$ ), yielding an expected total cost of $1,530,759 €$ when taking into account the resale values.

For the Nissan vehicles, the obtained quasi-optimal solution recommends the use of 15 electric vehicles during 47 months with a partial renewal action every 19 months. Each month, each vehicle will travel $24,000 \mathrm{~km}$ (i.e., $800 \mathrm{~km}$ per day). For these electric vehicles, the expected total cost is valued at $1,189,316 €$ (i.e., $0.070 € / \mathrm{km}$ ). Regarding the fuel vehicles, only one has to be acquired and used during 5 months with an average usage rate of $16,000 \mathrm{~km}$ per month (533 km/day) and without any partial renewal action (the obtained value of $m_{i}$ is greater than $Y_{i}$ ). The expected total cost is $10,767 €$ (i.e., $0.135 € / \mathrm{km}$ ) for this vehicle. The use of fuel and electric vehicles generate an expected total cost of 1,200,082 $€$.

There are similarities between the two examples. The use of electric vehicles is favored due to the lower total cost per kilometer $(€ / \mathrm{km})$. For these vehicles, the average usage rate is practically at the maximum permitted level. However, a nuance should be noted for example 1 (Renault vehicles), due to the characteristics of the battery. The latter has a range of $160 \mathrm{~km}$ and can be recharged up to 1200 times, allowing it to travel 192,000 km with one battery. Traveling $500 \mathrm{~km}$ more per month $\left(v_{2}=24,000 \mathrm{~km}\right)$ would require the purchase of another battery. The fuel vehicles are only used to supplement the number of kilometers to be traveled, where the use of additional electric vehicles would exceed by far the desired total number of kilometers $K$. Even if the total cost per $\mathrm{km}$ for the fuel vehicles is higher, traveling a shorter distance is economically more interesting (for example, for the Nissan vehicles, $80,000 \times 0.135 \ll 1,128,000 \times 0.070)$.

\section{Adjustment of the Preventive Maintenance Plan in Case of a Health Crisis}

Let us consider here that in the light of what preceded, and using the proposed model and numerical algorithms, the decision is made about the size and the typology of the vehicle fleet and the vehicles are acquired, and start being used. The potential occurrence of a health crisis like the widespread COVID-19 pandemic can be considered, with containment measures imposed during the period of use of the vehicles. Most likely, such a situation would make it impossible to perform PM actions during the containment (only repairs are allowed, to avoid stopping the missions of the vehicles; repairs are part of the vital logistics activities that must be maintained during the containment). The absence of PM during the containment period will necessarily impact the degradation of the vehicles and the evolution of their failure rate.

Hence, a new PM schedule must be adopted after the containment exit.

Suppose the containment period begins at a certain date $C$ from the start of the exploitation period of the vehicles. It lasts a period $\Delta C$ before the situation gets back to normal at $C+\Delta C$ (see Figure 3).

Let $m_{i}{ }^{\prime}$ be the new PM period to be adopted after the end of the containment period. 


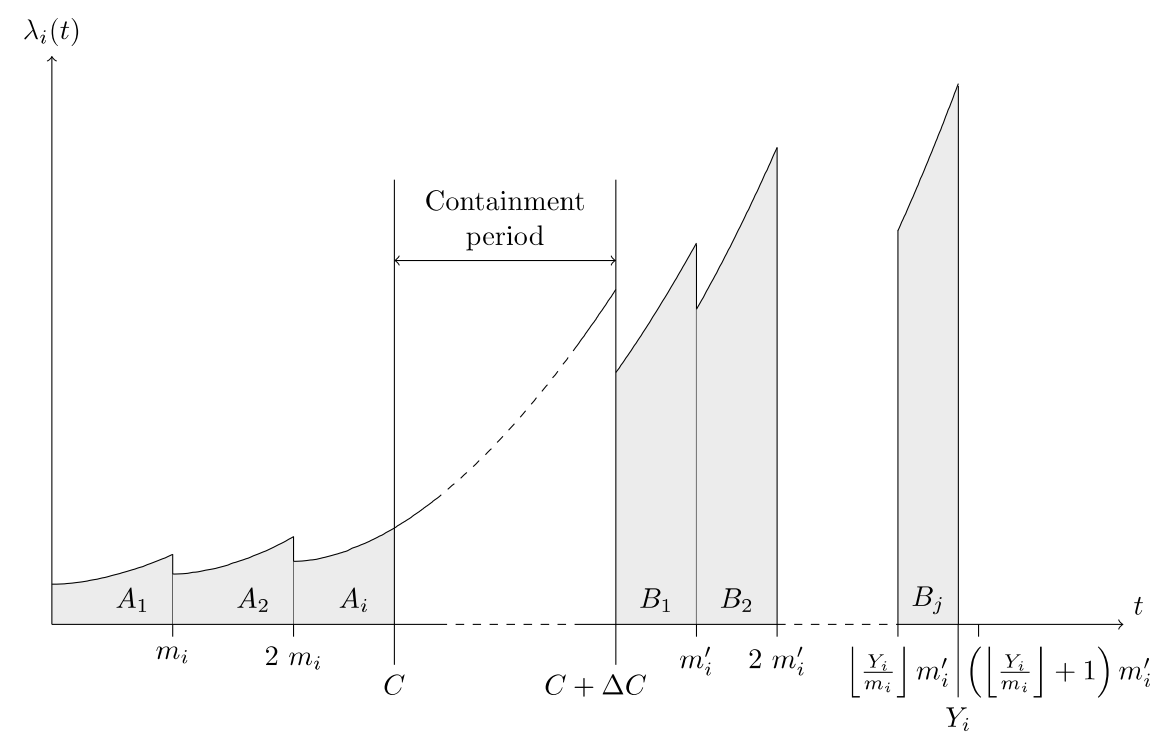

Figure 3. Evolution of the vehicle failure rate with partial renewals every PM period $m_{i}$ or $m_{i}{ }^{\prime}$ considering the containment period.

Thus, for this new situation with three periods (before, during, and after the containment), the average number of minimal repairs, noted $\varnothing\left(Y_{i}, m_{i}, m_{i}{ }^{\prime}, C, \Delta C\right)$, over a period of use of a vehicle of type $i$ with a given PM period $m_{i}$ up to the date $C$, then a period without PM for a period $\Delta C$ and finally a period of use with a given new PM period $m_{i}^{\prime}$ can be expressed as follows:

$$
\begin{aligned}
\varnothing\left(Y_{i}, m_{i}, m_{i}{ }^{\prime}, C, \Delta C\right) & \\
= & \sum_{j=1}^{\left\lfloor\frac{C}{m_{i}}\right\rfloor} \int_{0}^{m_{i}} e^{(j-1) \cdot \alpha} \cdot \lambda_{i}(x) d x+\int_{0}^{(C+\Delta C)-\left\lfloor\frac{C}{m_{i}}\right\rfloor \cdot m_{i}} e^{\left\lfloor\frac{C}{m_{i}}\right\rfloor \cdot \alpha} \cdot \lambda_{i}(x) d x \\
& \left.+\sum_{j=\left\lfloor\frac{C}{m_{i}}\right\rfloor+1}^{\sum_{i}^{\prime}{ }^{\prime}}\right\rfloor \int_{0}^{m_{i}{ }^{\prime}} e^{(j-1) \cdot \alpha} \cdot \lambda_{i}(x) d x \\
& +\int_{0}^{\left(Y_{i}-(C+\Delta C)\right)-\left\lfloor\frac{Y_{i}-(C+\Delta C)}{m_{i}^{\prime}}\right\rfloor \cdot m_{i}{ }^{\prime}} e^{\left\lfloor\frac{Y_{i}-(C+\Delta C)}{m_{i}^{\prime}}\right\rfloor \cdot x} \cdot \lambda_{i}(x) d x .
\end{aligned}
$$

The first term of the sum expresses the number of failures for the complete intervals between two PM of periodicity $m_{i}$. The second term stands for the average number of failures for the last (incomplete) interval until the start of the containment period. The third term corresponds to number of failures for all complete intervals between two PM of periodicity $m_{i}{ }^{\prime}$, i.e., after the confinement period. Finally, the fourth term expresses the average number of failures until the end of the use of the vehicles (incomplete interval).

Hence, the new expected total maintenance cost per vehicle is given by

$$
C_{M i}=C_{M C i} \cdot \varnothing\left(Y_{i}, m_{i}, m_{i}{ }^{\prime}, C, \Delta C\right)+C_{M P i} \cdot\left(\left\lfloor\frac{Y_{i}}{m_{i}{ }^{\prime}}\right\rfloor+\left\lfloor\frac{Y_{i}-(C+\Delta C)}{m_{i}{ }^{\prime}}\right\rfloor\right) .
$$

This average total cost of maintenance is minimized by looking for the optimal new PM period $m_{i}{ }^{\prime}$. For that, a numerical procedure has been used, incrementally varying the values of $m_{i}{ }^{\prime}$.

In order to illustrate the changes in the PM strategy because of the health crisis, let us refer to the numerical examples discussed in the previous section and consider, for instance, a containment period that starts after $C=18$ months and lasts $\Delta C=6$ months.

Given the results in Table 5 (Renault fuel vehicles to be used for $Y_{1}=13$ months and Nissan fuel vehicles to be used for $Y_{2}=5$ months), it appears that this containment period 
will concern only electric vehicles that are to be used for 57 and 47 months for Renault and Nissan, respectively.

The following results are obtained:

For the first example with Renault electric vehicles, a PM must be carried out at the start of the post-containment period, which means at 24 months. Thereafter, PM must be performed every 7 months, which will result in a total of 5 PM actions.

For one vehicle, the total expected maintenance cost is $7891 €$ whereas if the initial PM period $\left(m_{i}=23\right.$ months) was kept after the containment, the total average maintenance cost would have been equal to $9617 €$.

For the second example, Nissan electric vehicles, a PM action must be performed at the start of the post-containment period and then every 8 months (after 32 and 40 months). With this adjustment of the PM period $\left(m_{i}{ }^{\prime}=8\right.$ months), the expected total cost of maintenance, for a given vehicle, is equal to $6671 €$. It is lower than the expected maintenance cost $(7707 €)$ obtained if the initial PM period ( $m_{i}=19$ months) was kept after the containment.

Hence, it is clear for both types of vehicles that adjusting the PM period after the containment is economically justifiable. It is also technically sound since due to the accumulated degradation during the containment in absence of PM, PM actions become more frequent during the post-containment period. Indeed, in both examples, the new PM period $m_{i}{ }^{\prime}$ after the containment period is smaller than the initial one, $m_{i}$.

In terms of practical implications, this work comes in the context of the increasing importance of sustainability in the business world and the growing pressure on companies to reduce the environmental impact of their logistics, particularly in transportation. The developed model allows helping the decision maker to select the appropriate size of a fleet of vehicles determining the number of vehicles to be acquired considering simultaneously the environmental impact of each type of vehicles, their reliability, and their maintenance. The duration of the use of each vehicle and its average recommended usage rate are also provided.

Currently, the vehicle market is composed of several technologies with different characteristics such as autonomy, $\mathrm{CO}_{2}$ emissions, etc. Fuel type is still the most widely used technology, followed by hybrid vehicles and then fully electric vehicles (http:// carlabelling.ademe.fr/chiffrescles/r/venteParTypeEnergie). Two types $(N=2)$ of vehicles have been considered in this work (fuel and electric), but the proposed mathematical model allows easily extending to several types of vehicles of whatever brands. It will only be necessary to adapt the different costs to each type of vehicle. The formulations of acquisition, maintenance, and environmental impact costs are similar for the different types. However, operation costs should be formulated differently due to varying technologies. Maintenance costs are based on the failure probability distribution and maintenance actions consist of imperfect PM (partial renewals), at fixed intervals and minimal repairs when breakdowns occur.

\section{Conclusions and Prospects}

In this paper, a framework was studied for modeling a vehicle fleet dedicated to conduct logistics missions that are characterized by several kilometers to be traveled during a maximum required time period. The composition of the vehicle fleet should minimize the expected total cost to be incurred, which is equal to the difference between the total of the expected partial costs (acquisition, maintenance, operation, and environmental impact) and the resale value. In this perspective, a mixed integer non-linear programming (MINLP) model has been developed. For each type of vehicle, this model involves four decision variables, namely the number of vehicles, and for each vehicle, the number of months of use, the period to perform PM, and the average usage rate.

Hence, for two types $(N=2)$ of vehicles (fuel and electric), eight decision variables (four for each of the two types of vehicle) have been considered. A metaheuristic (genetic algorithm) has been used to find a quasi-optimal solution within a reasonable computational time (few minutes) for any instance of the problem. Two numerical examples have 
been presented. The first one considering Renault utility fuel and electric vehicles, and the second one involving fuel and electric Nissan vehicles.

The situation of an eventual health crisis and containment after the acquired vehicles start being used has also been considered. Therefore, it was assumed that only repairs would be allowed during the containment period. PM actions would be impossible to perform. The expected total cost of maintenance has been reformulated accordingly, and a new adjusted PM period has been computed such that the total average cost of maintenance is minimized. The obtained results showed that a shorter PM period should be adopted during the post-containment period. It was also observed that the total maintenance cost with the adjusted PM period is lower than the one that would have been incurred in case the initial PM period is kept after the containment exit.

This work can be extended in different ways by trying to answer the following questions: should the purchase and resale of vehicles be favored or is it economically more profitable to lease the vehicles? Is it advisable to resell the vehicles directly after having used them or should these vehicles be rented out?

Furthermore, work currently under consideration consists in making the proposed strategy not only economically profitable but also environmentally profitable. This can be done, on one hand, by adding non-economic constraints in relation with the choice of vehicle types such as the maximum permissible amount of $\mathrm{CO}_{2}$ emitted, and on the other hand, by including waste management related to the partial renewals of vehicles components.

Finally, numerical algorithms and metaheuristics other than $G A$ can be considered and compared for solving different instances of the problem.

Author Contributions: Conceptualization, S.D. and J.S.; methodology, S.D., J.S. and M.B.M.; software, J.S. and M.B.M.; validation, J.S., S.D. and M.B.M.; formal analysis, J.S., S.D., M.B.M. and A.C.; resources, M.B.M.; writing-original draft preparation, M.B.M., J.S., S.D., A.C.; writing-review and editing, M.B.M., J.S., S.D., A.C.; supervision, A.C.; project administration, M.B.M., S.D. All authors have read and agreed to the published version of the manuscript.

Funding: This research received no external funding.

Institutional Review Board Statement: Not applicable.

Informed Consent Statement: Not applicable.

Conflicts of Interest: The authors declare no conflict of interest.

\section{Appendix A}

Table A1. Vehicle references related to the example of Section 4.

\begin{tabular}{|c|c|c|}
\hline \multirow[b]{2}{*}{$\mathrm{CU}_{\mathrm{CO} 2}$} & & References \\
\hline & & $\begin{array}{l}\text { (a) https://www.ecologique-solidaire.gouv.fr/sites/default/files/prix-carbone_4p_DEF_Fr.pdf } \\
\text { (accessed on } 6 \text { March 2021) }\end{array}$ \\
\hline \multicolumn{3}{|r|}{ Fuel Vehicle } \\
\hline$C_{A 1}$ & $\begin{array}{l}\text { (Renault) } \\
\text { (Nissan) }\end{array}$ & $\begin{array}{c}\text { (b) https:// professionnels.renault.fr/vehicules-utilitaires/kangoo-express.html (accessed on } 6 \text { March 2021) } \\
\text { (c) https:/ / www.autoplus.fr/nissan/nv250/prix-neuf/Nissan-NV250-Fourgon-1.5-dCi-95-OPTIMA- } \\
\text { Fourgon-184327.html (accessed on 6 March 2021) }\end{array}$ \\
\hline eff $f_{1}$ & $\begin{array}{l}\text { (Renault) } \\
\text { (Nissan) }\end{array}$ & $\begin{array}{l}\text { [13] and link (b). } \\
\text { [13] and (d) https:/ / www-europe.nissan-cdn.net/content/dam/Nissan/fr/brochures / Brochures- } \\
\text { vehicules/Brochure_NV250-Fourgon.pdf (accessed on } 6 \text { March 2021) }\end{array}$ \\
\hline$g_{1}$ & $\begin{array}{l}\text { (Renault) } \\
\text { (Nissan) }\end{array}$ & $\begin{array}{l}\text { [13] and link (b). } \\
\text { [13] and link (d). }\end{array}$ \\
\hline
\end{tabular}


Table A1. Cont.

\begin{tabular}{|c|c|c|}
\hline \multirow[b]{2}{*}{$C U_{\mathrm{CO} 2}$} & & References \\
\hline & & $\begin{array}{l}\text { (a) https://www.ecologique-solidaire.gouv.fr/sites/default/files/prix-carbone_4p_DEF_Fr.pdf } \\
\text { (accessed on } 6 \text { March 2021) }\end{array}$ \\
\hline \multicolumn{3}{|r|}{ Electric Vehicle } \\
\hline$C_{A 2}$ & $\begin{array}{l}\text { (Renault) } \\
\text { (Nissan) }\end{array}$ & $\begin{array}{l}\text { (e) https://professionnels.renault.fr/vehicules-electriques/kangoo-ze.html (accessed on } 6 \text { March 2021) } \\
\text { (f) https://www-europe.nissan-cdn.net/content/dam/Nissan/fr/brochures/Brochures-vehicules/ } \\
\text { eBrochure_e-NV200_Fourgon.pdf (accessed on } 6 \text { March 2021) }\end{array}$ \\
\hline$\theta$ & $\begin{array}{l}\text { (Renault) } \\
\text { (Nissan) }\end{array}$ & $\begin{array}{c}\text { Link (e) } \\
\text { (g) https: / / www.nissan.fr/vehicules/neufs/e-nv200/autonomie-recharge.html (accessed on } 6 \text { March 2021) }\end{array}$ \\
\hline$N b_{\text {Max Ch }}$ & $\begin{array}{l}\text { (Renault) } \\
\text { (Nissan) }\end{array}$ & $\begin{array}{l}\text { (h) https: / / easyelectriclife.groupe.renault.com/fr/au-quotidien/recharge/quel-est-la-duree-de-vie-d- } \\
\text { une-voiture-electrique/ (accessed on } 6 \text { March 2021) } \\
\text { (i) https: / / www.automobile-propre.com/dossiers/la-duree-de-vie-des-batteries-des-voitures-electriques / } \\
\text { (accessed on } 6 \text { March 2021) }\end{array}$ \\
\hline$C_{C h}$ & $\begin{array}{l}\text { (Renault) } \\
\text { (Nissan) }\end{array}$ & 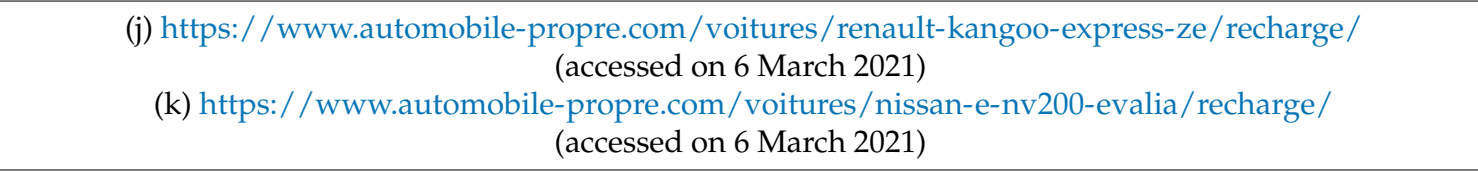 \\
\hline eff $f_{2}$ & $\begin{array}{l}\text { (Renault) } \\
\text { (Nissan) }\end{array}$ & $\begin{array}{l}\text { [13] and link (b). } \\
\text { [13] and link (f). }\end{array}$ \\
\hline$g_{2}$ & $\begin{array}{l}\text { (Renault) } \\
\text { (Nissan) }\end{array}$ & $\begin{array}{l}\text { [13] and link (b). } \\
\text { [13] and link (f). }\end{array}$ \\
\hline
\end{tabular}

\section{References}

1. Rezg, N.; Sofiene, D.; Zied, H. Maintenance Optimization for Transport Vehicles in a Supply Chain. Logist. Transp. 2014, 24, 7-14.

2. Troudi, A.; Sofiene, D.; Addouche, S. An optimal maintenance policy for transport vehicles in a supply chain under infrastructure/environment constraints. In Proceedings of the 45th International Conference on Computers \&Industrial Engineering, Metz, France, 28-30 October 2015.

3. Dhahri, A.; Zidi, K.; Ghédira, K. A Variable Neighborhood Search for the Vehicle Routing Problem with Time Windows and Preventive Maintenance Activities. Electron. Notes Discret. Math. 2015, 47, 229-236. [CrossRef]

4. Dhahri, A.; Mjirda, A.; Zidi, K.; Ghedira, K. A VNS-based Heuristic for Solving the Vehicle Routing Problem with Time Windows and Vehicle Preventive Maintenance Constraints. Procedia Comput. Sci. 2016, 80, 1212-1222. [CrossRef]

5. Ndhaief, N.; Bistorin, O.; Rezg, N. An Improved Distribution Policy with a Maintenance Aspect for an Urban Logistic Problem. Appl. Sci. 2017, 7, 703. [CrossRef]

6. Rashidnejad, M.; Ebrahimnejad, S.; Safari, J. A bi-objective model of preventive maintenance planning in distributed systems considering vehicle routing problem. Comput. Ind. Eng. 2018, 120, 360-381. [CrossRef]

7. Jbili, S.; Chelbi, A.; Radhoui, M.; Kessentini, M. Integrated strategy of Vehicle Routing and Maintenance. Reliab. Eng. Syst. Saf. 2018, 170, 202-214. [CrossRef]

8. Vujanovic, D.; Momcilovic, V.; Medar, O. Influence of an integrated maintenance management on the vehicle fleet energy efficiency. Therm. Sci. 2018, 22, 1525-1536. [CrossRef]

9. Wang, T.; Li, M.; Hu, H. Berth allocation and quay crane-yard truck assignment considering carbon emissions in port area. Int. J. Shipp. Transp. Logist. 2019, 11, 216-242. [CrossRef]

10. Sawik, B.; Faulin, J.; Pérez-Bernabeu, E. Multi-Criteria Optimization for Fleet Size with Environmental Aspects. Transp. Res. Procedia 2017, 27, 61-68. [CrossRef]

11. Donateo, T.; Ingrosso, F.; Licci, F.; Laforgia, D. A method to estimate the environmental impact of an electric city car during six months of testing in an Italian city. J. Power Sources 2014, 270, 487-498. [CrossRef]

12. Rios-Torres, J.; Liu, J.; Khattak, A. Fuel consumption for various driving styles in conventional and hybrid electric vehicles: Integrating driving cycle predictions with fuel consumption optimization. Int. J. Sustain. Transp. 2018, 13, 123-137. [CrossRef]

13. Prud'Homme, R.; Koning, M. Electric vehicles: A tentative economic and environmental evaluation. Transp. Policy 2012, 23, 60-69. [CrossRef]

14. Macrina, G.; Pugliese, L.D.P.; Guerriero, F. The Green-Vehicle Routing Problem: A Survey. In Modeling and Optimization in Green Logistics; Springer: Cham, Switzerland, 2020; pp. 1-26.

15. Gertsbakh, I. Reliability Theory: With Applications to Preventive Maintenance; Springer: New York, NY, USA, 2013.

16. LegiPermis. Décote Voiture: Le Calcul. 2020. Available online: https://www.legipermis.com/estimation-cote-voiture/decoteauto.html (accessed on 30 May 2020). 
17. Le Point. Voiture Électrique: $80 \%$ de Décote en 3ans. 2013. Available online: https://www.lepoint.fr/automobile/voitureelectrique-80-de-decote-en-3-ans-16-12-2013-1770244_646.php (accessed on 30 May 2020).

18. Ponsich, A.; Azzaro-Pantel, C.; Domenech, S.; Pibouleau, L. Some Guidelines for Genetic Algorithm Implementation in MINLP Batch Plant Design Problems. In Natural Computing Series; Springer: Heidelberg/Berlin, Germany, 2008; pp. $293-315$.

19. Deep, K.; Singh, K.P.; Kansal, M.; Mohan, C. A real coded genetic algorithm for solving integer and mixed integer optimization problems. Appl. Math. Comput. 2009, 212, 505-518. [CrossRef]

20. Deb, K. An efficient constraint handling method for genetic algorithms. Comput. Methods Appl. Mech. Eng. 2000, 186, 311-338. [CrossRef] 